\title{
US DEPARTMENT OF DEFENSE MODELING AND SIMULATION: NEW APPROACHES AND INITIATIVES
}

\author{
Thomas ALLEN ${ }^{1}$
}

\begin{abstract}
In order to more effectively analyze strategic, force structure, and systems choices associated with the national security environment of the $21^{\text {st }}$ Century, the US Department of Defense is attempting to improve its approach to the development, management and application of Modeling and Simulation (M\&S). It has established a new structure to oversee and integrate M\&S activity and directed DoD communities to develop internal business plans to focus that effort. The Analysis Community has responded by identifying desired analytic M\&S goals, measuring current capabilities, prioritizing capability gaps, and then outlining potential solutions. These activities are being captured as part of an analysis M\&S business plan product and process. This paper notes that a key desired outcome is improved M\&S to address three areas of particular concern: Irregular Warfare and the Global War on Terror; Stability, Security, Transition and Reconstruction operations; and Joint, Interagency, and Multinational operations. In these areas, the Department is seeking a broad, collaborative approach to engage interagency and allied partners in developing and using new analytic approaches and tools.
\end{abstract}

Keywords: Modeling and Simulation $(\mathrm{M} \& \mathrm{~S})$; Management; Strategy; Analysis; Business Plan; Irregular Warfare; Global War On Terror (GWOT); Stability, Security, Transition and Reconstruction (SSTR); Joint, Interagency, and Multinational (JIM).

Over the past decade, the United States Department of Defense (DoD) has recognized a need for change, both in terms of its national security strategy and the models, simulations and analyses needed to support that strategy. As the Department completed its last major Quadrennial Defense Review (QDR) and articulated a new direction, it was apparent that the tools and analytic capabilities available to help shape key decisions were not as robust as needed to address the full set of options being considered. The Defense Modeling and Simulation Office (DMSO), which had been established in the mid-1990s to coordinate the development of modeling and simulation (M\&S) across the Department, had not been successful in stimulating the crea- 


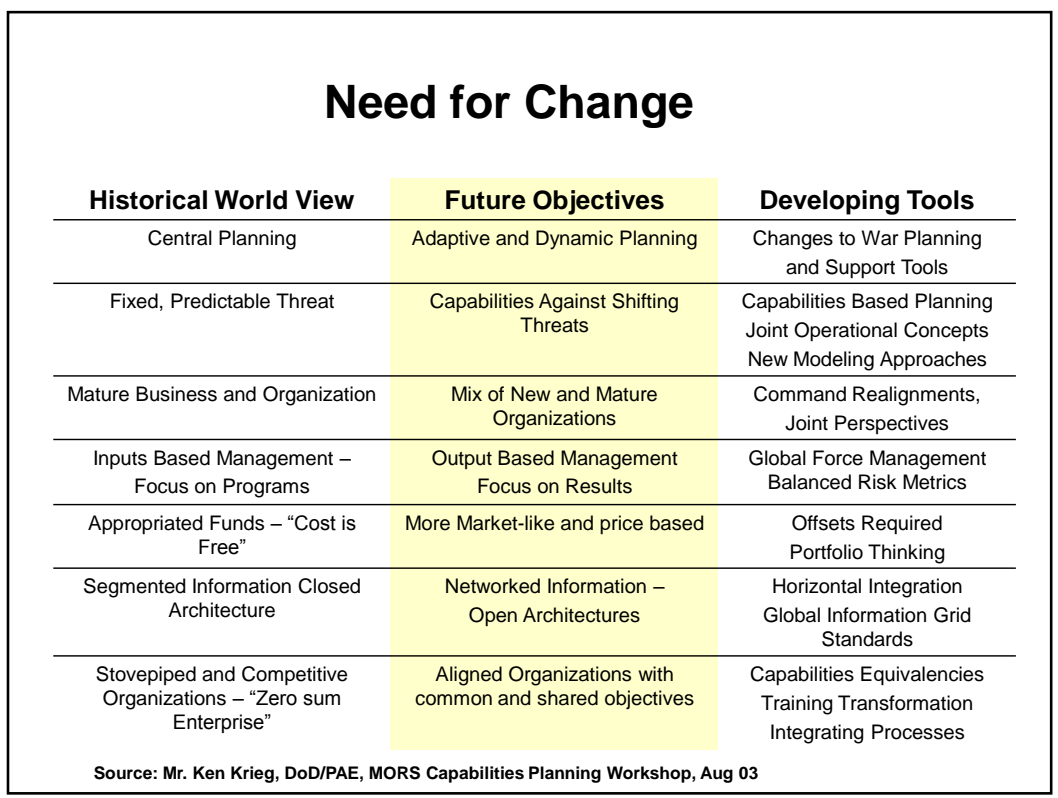

Figure 1: Need for Change.

tion of new tools that could better inform the strategic choices faced by the Department in the $21^{\text {st }}$ Century. In 2005, DoD leadership began establishing a new structure to address the common M\&S needs of the Department and reorganized DMSO to become what is now the Modeling and Simulation Coordination Office (MSCO). This paper outlines the specific concerns that led to a new direction in US military M\&S development. It also describes how the analytic community in particular is creating a new business planning process to articulate a community vision and set specific objectives in the areas of methodology, tools, data, intellectual capital, research and cross-community activities to instantiate that vision. The paper then discusses how the business process has compared these objectives to current M\&S capabilities in order to identify and prioritize gaps in the M\&S needed to support the vision, and outlines some specific solution areas that could benefit by collaboration with and contribution from its international partners.

\section{Need for Change}

Figure 1 illustrates many of the motivations for the change in US national security strategy and the types of tools decision-makers and analysts require to support the assessment of options to support that change. Throughout the Cold War era, centralized planning characterized the approach taken to address the challenge to the Western Alliance posed by the post-World War II Soviet Union. The bi-polar competition 
between the West and the East has now been replaced by a new security environment that includes hostile non-state actors with global reach, shifting regional tensions, failed states, and a change in emphasis from major combat operations to a broader spectrum of military activity that also includes peacekeeping, counter-terrorism, counter-narcotics, and counter insurgency. Addressing this new environment requires adaptive and dynamic planning and the development of military capabilities that can address a variety of threats using a mixture of new and mature organizations that maintain a joint, interagency, and coalition perspective.

The change in environment has led in turn to a requirement for new management approaches within the Department, shifting from a focus on inputs to a focus on outputs. Analysis, and the modeling and simulation tools that support it, is in high demand by US decision-makers to assess the strategy, force structure, and new system options needed to succeed in this new environment. At the same time, the information revolution that emerged in the last decades of the $20^{\text {th }}$ Century is making possible new ways to command and control military forces as well as suggesting improved methods to manage the business of the Department. DoD has recognized the issues associated with stove-piped and competitive organizations and is attempting to implement a cultural change to identify common approaches that will improve efficiency and lead to a more open and collaborative business environment. In one sense, Operation Iraqi Freedom was the first truly joint major combat operation of the $21^{\text {st }}$ century, moving from Desert Storm's synchronized military operations conducted by the separate military Services, to fully integrated activities on the battlefield. As change has occurred or the need for change has been recognized, so has the need for more flexible and collaborative analytic, planning, and decision support tools that can address both the desired decision-making environment and the broader range of military operations for which the military must now prepare.

Creating new tools in the midst of transformational change in the security environment is a major challenge. As the analytic community attempts to meet the demands of security decision-makers, it has too often contributed to the development of unreasonable expectations regarding the potential of new tools to address the broader ranges of issues now under consideration. The shortcomings of military models can be explained by a number of factors, not the least of which is the key role played by less predictable human factors in all aspects of military activity. At the same time, the analysis community needs to help decision-makers keep M\&S development in context while they conduct the important research necessary to address such topics as irregular warfare and terrorism. Insights from several analysts and decision-makers may be helpful in establishing appropriate expectations. These include:

- "All models are wrong - some are useful" (George Box); 
- "If you build a tool that even idiots can use, then rest assured, idiots will use it" (Wilbur Payne);

- "Models provide insights and sharpen critical thinking - they do not make decisions" (Ernest Seglie);

- "In the end, the good judgment of the analyst is always the most essential tool for successful operations research" (Gen Larry Welch);

- "Before using a model - understand how it works" (Jim Bexfield);

- "As analysts, we tend to not account for the degree to which smart (or dumb) use of forces can dominate the outcome of a conflict" (BGen Leon Goodson).

\section{Improving DoD M\&S Management}

The Defense Modeling and Simulation Office was established in the early 1990s as a focal point for DoD M\&S Development. The Office was inaugurated as a response to Congressional interest in $\mathrm{M} \& \mathrm{~S}$ as well as to meet senior Departmental leadership desires to improve the efficiency and effectiveness of $\mathrm{M} \& \mathrm{~S}$ development across all aspects of the Defense enterprise. Oversight of DMSO was provided by a senior executive committee led by the Acquisition and Research Community. In the fall of 2005, after receiving a report from a Senior Advisory Group chartered to address DoD $M \& S$, senior leaders directed a full internal program review of the area. In response to that review, the Department initiated expanded oversight of M\&S through a new executive committee led by the "Tri-chairs" of Acquisition, Training and Analysis, as represented by senior officials of the Office of the Under Secretary of Defense for Acquisition, Technology and Logistics (USD/AT\&L); the Office of the Under Secretary of Defense for Personnel and Readiness (USD/P\&R); and the Office of the Director for Program Analysis and Evaluation (PA\&E). DMSO was reorganized and refocused to become the Modeling \& Simulation Coordination Office (M\&S CO). The new management structure focused on coordinating M\&S activities across the Department with specific support given to high priority Common and Cross-cutting M\&S initiatives. The Tri-chairs now meet regularly with a new Defense M\&S Steering Committee (M\&S SC) that includes representatives from Defense offices in Policy, Intelligence, and Networks and Information Integration, as well as the Joint Chiefs of Staff, the Joint Forces Command, the Services and the Defense Intelligence Agency. The M\&S SC has directed that each of the major defense M\&S communities create and publish a community business plan that not only will guide each community's M\&S development, but also will be used to help identify the common and cross-cutting capabilities that are to be the focus of the Steering Committee's attention. Within the analytic community, the Joint Analytic Data Management Steering Committee (JADM SC), led by PA\&E and Policy, and with analytic representatives 


\section{New DoD M\&S Management Approach}

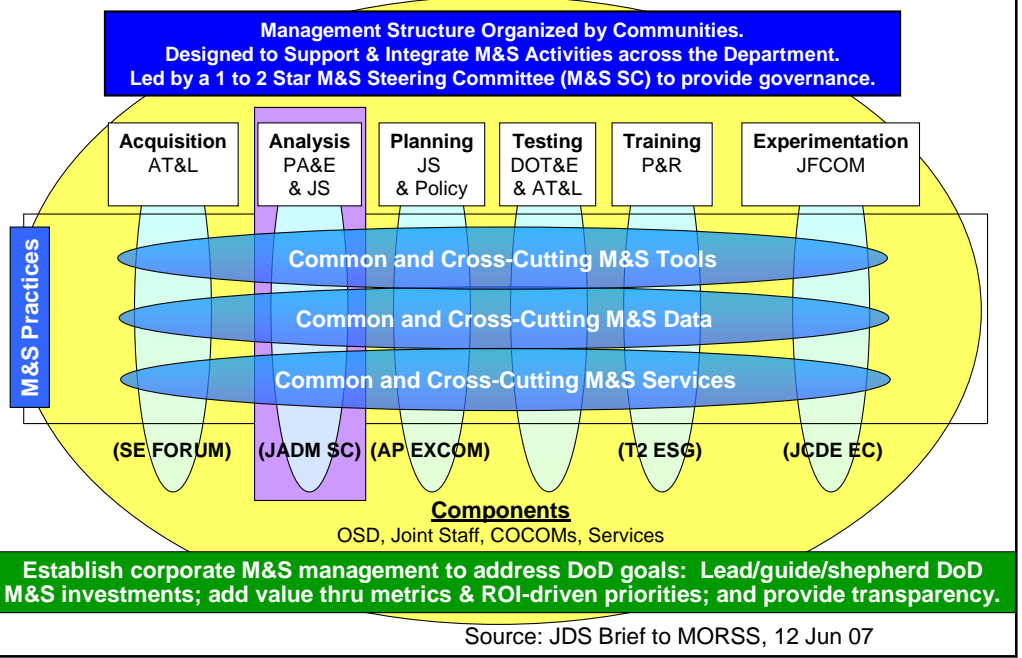

Figure 2: New DoD M\&S Management Approach.

of the same organizations that participate in the M\&S SC, has guided the development of an analysis M\&S business plan. The new DoD Management approach is illustrated in Figure 2.

The purpose of the business plans is to mature and institutionalize community-specific $\mathrm{M} \& \mathrm{~S}$ capabilities, plans, and organization. In addition, by capturing the current capabilities and anticipated future M\&S needs of each community, the document provides a source for identifying community validated requirements, and therefore a basis for investment in new M\&S that transcends any rationale developed by the individual participating organizations. The business plans themselves also serve as a basis for identifying common and crosscutting tools, data, services, and practices, which can then serve as a basis for the M\&S SC to establish helpful Departmental policies in this area and to promulgate them across communities.

The content of these business plans include a discussion of each community's M\&S scope, vision, and current capabilities. In addition, the plans list the organizations and individuals that make up the membership of the community, along with any institutional governance arrangements and methods of communication. Finally, the plans provide a section on $M \& S$ development required to achieve each community's vision and objectives, current initiatives based on gaps in tools, data, and services, and a prioritized list of potential community-specific projects that could address any remaining gaps. 


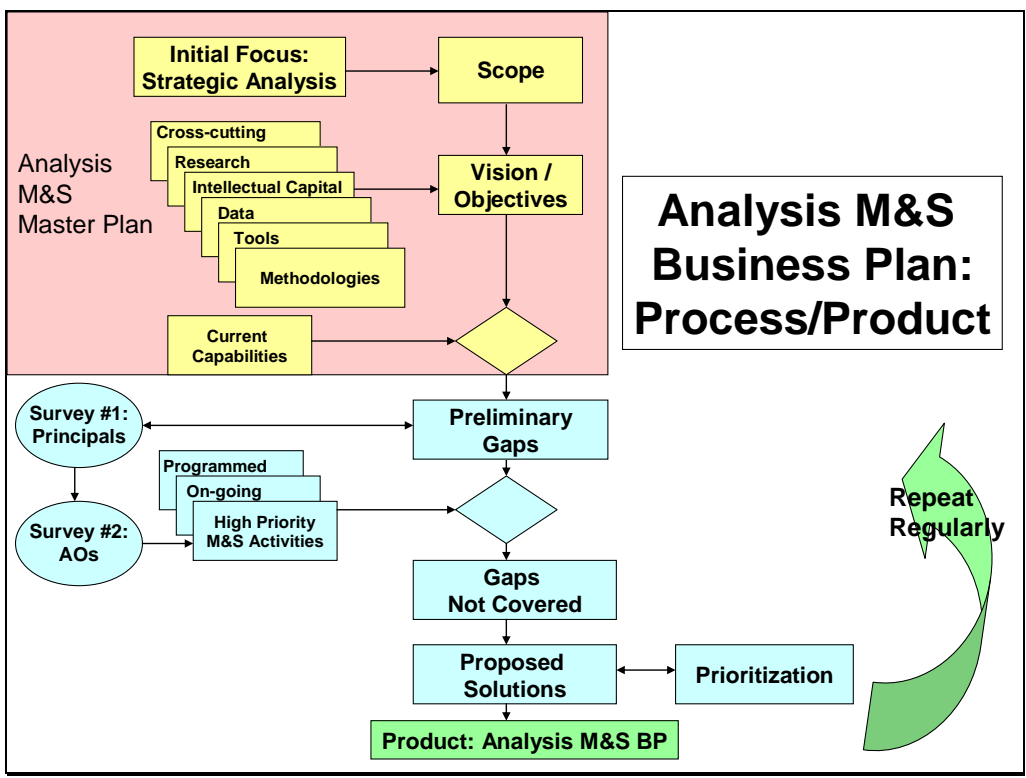

Figure 3: Analysis M\&S Business Plan Process and Product.

\section{Analysis M\&S Business Planning}

Figure 3 characterizes the process that the Analytic Community employed to identify, characterize, and prioritize analysis $M \& S$ gaps and solutions. The inaugural version of the Analysis M\&S Business Plan focused on strategic analysis, with the intention that a broader range of analysis would be addressed in future iterations. Thus, initial attention was limited to those strategic issues that are relevant to major Department activities such as the development of the National Security Strategy and the conduct of the Quadrennial Defense Review (QDR). Consistent with the initial scope, the community adopted a vision for analysis M\&S along with associated objectives in six key areas: methodology, tools, data, intellectual capital, research, and cross-cutting (i.e., cross-M\&S community) activities. These objectives provided a standard against which to assess current $M \& S$ capabilities.

Seventy three preliminary gaps were identified, based on a comparison of current capabilities to those standards. In order to prioritize those gaps, a research team developed a survey to elicit the views of key leaders of the analysis M\&S community. Analyzing the responses to that survey achieved three objectives: it clarified community priorities with respect to the gaps, it elicited 33 additional gaps, and it served to identify key M\&S activities (and Actions Officers) that are currently pursuing programs to address some of the gaps. Following up with the Action Officers, a second 


\section{Scope of Analysis M\&S}

- Support national security strategic-level assessment, force structure, and force transformation issues

- Address the strategic requirements of Irregular Warfare (IW), War on Terror (WOT), Homeland Defense (HD), and conventional campaigns

- Deterrence

- Interdiction

- WMD elimination

- Information Operations (IO)

- COIN / stability operations

- Major combat strike

- Stability operations

- Reconstruction support

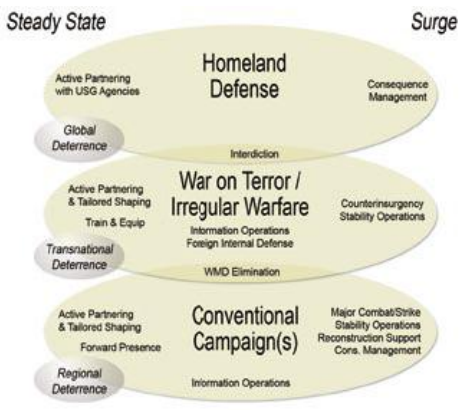

- Consider other key factors to include political, economic, social, informational and infrastructure

Source: Draft Analysis M\&S Business Plan, May 07

Figure 4: Initial Scope of Analysis M\&S.

survey was developed to help describe these on-going efforts and to characterize the extent to which they expect to close specific gaps.

The result of those efforts was a prioritization of key gaps and the identification of those that are not being addressed adequately by current projects. These results provided the basis for developing potential solutions to address high priority residual gaps. Later sections will focus on some of the solutions that emerged from this process.

In the meantime, the business plan process is being institutionalized so that analysis $\mathrm{M} \& \mathrm{~S}$ progress can be updated on a regular basis to reflect contributions by the ongoing projects. In addition, the analytic leadership will be solicited on a regular basis to ensure the vision and objectives continue to reflect the long-term goals of the community, with gaps and priorities updated both to reflect the fielding of new capabilities and to incorporate any additional requirements associated with future military analysis. The business plan will serve as both a "living" document to measure the current state of analysis $M \& S$ development and as the basis for a recognized process that tracks development activity and improvement through time. 


\section{Scope of the Analysis M\&S Business Plan}

Figure 4 illustrates the initial scope of the analysis $M \& S$ business planning process. As noted earlier, the purpose of the initial version is to support the development, fielding and application of appropriate $M \& S$ capabilities to support national security strategic-level assessment issues. These issues frequently address the full range of military operations subsuming all defined military phases of conflict from the initial phase of military planning and build-up through the final phase of enabling civil authority to take charge. The QDR, as one example of a major Departmental analytic effort, emphasized policy issues associated with both steady state and surge operations for Homeland Defense, the War on Terror/ Irregular Warfare, and conventional campaigns. Issues that emerged from the QDR in many cases transcend the military domain to include all aspects of the political, military, economic, social, informational, and infrastructure (PMESII) dimensions associated with a problem.

Figure 5 suggests how the challenge to the US military analysis community has changed over the past several years. From a strategy that focused on preparing for and winning major regional conflicts (with all other military activities considered to be subsumed under this major combat operation focus), the Department now recog-

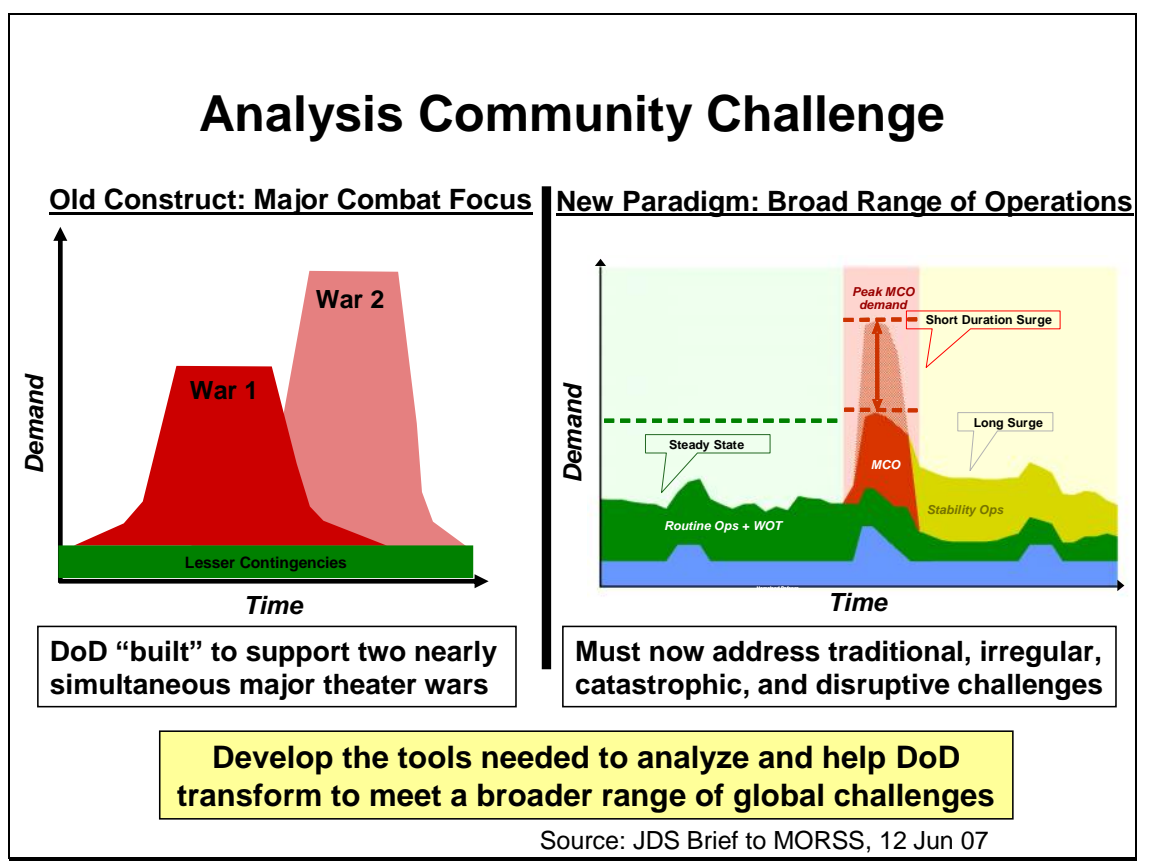

Figure 5: Shifting Focus to a Broad Range of Operations. 
nizes a broad range of military requirements, not all of which directly support major combat operations. Examples include the requirement for prolonged engagement in stability operations and on-going support to the global war on terror.

As a part of its business plan development, the analytic community convened a workshop in early March 2007 to focus on developing candidate solutions to prioritized gaps associated with the community's ability to address the much larger range of responsibilities and operations associated with the new security environment. In advance of that workshop, the analysis team surveyed analytic leadership to determine their assessment of the community's ability to address the full range of strategic issues and then used the results of that survey to inform the workshop of the perceived gaps and desired capabilities.

The workshop addressed three categories of gaps and potential solutions. These included key substantive issues that received high priority in the survey, such as irregular warfare and the war on terror; selected functional, cross-cutting issues such as Capability Based Assessment, and research issues, such as Complex Adaptive Systems; and finally a broad range of management issues, to included community governance, information exchange, intellectual capital, and selected data issues. The remainder of this paper addresses potential solutions to M\&S gaps that are being incorporated in the US DoD Analysis M\&S Business Plan, which are being circulated within the internal US military community and could involve its interagency and coalition partners.

Table 1 presents a list of the highest priority gaps identified by the US analytic community. The Table notes major gaps; categorizes them by general area such as data, methodology, or tools; and provides a Lickert scale rating of how important these gaps were perceived to be by both the senior leaders of the JADM SC, and a broader range of analytic leaders throughout the Department. The table identifies the top nine gaps with the Lickert scale responses signifying: very high $=5$; high $=4$; moderate $=$ 3 ; low $=2$; very low $=1$. A comparison of the results from the total population of respondents to the members of the JADM SC shows that, with one exception, the order of the priorities is the same for both classes of respondents, although the JADM SC consistently gave eight of the gaps slightly higher average ratings. The one exception to the rule was the gap, "Meet Quick-Turn information needs of decision makers," which received a noticeably lower priority from the JADM SC members.

The highest priority gaps focused on methodology, tools, and data issues associated with Irregular Warfare (IW)/ Global War on Terrorism (GWOT) and Stability, Security, Transition, and Reconstruction (SSTR). Solutions discussed in the remainder of this paper include these two areas, plus approaches to Joint, Interagency and Multinational Analysis, which fell in the next tier of priority. 


\section{Survey Perspectives: All Respondents versus Primary Joint Analytic Leaders}

\begin{tabular}{|l|l|l|c|c|}
\hline Gap Area & \multicolumn{1}{|c|}{$\begin{array}{c}\text { Sub- } \\
\text { Category }\end{array}$} & \multicolumn{1}{|c|}{ Gap } & $\begin{array}{c}\text { Average } \\
\text { Response } \\
\text { (AII) }\end{array}$ & $\begin{array}{c}\text { Average } \\
\text { Response } \\
\text { (JADM SC) }\end{array}$ \\
\hline Data & Scenarios & Defeating terrorist networks & 4.38 & 4.63 \\
\hline Methodology & MoMs & War on Terror/Irregular Warfare & 4.31 & 4.50 \\
\hline Tools & $\begin{array}{l}\text { QDR } \\
\text { Challenges }\end{array}$ & Defeating terrorist networks & 4.13 & 4.38 \\
\hline Tools & Domains & Irregular Challenges & 4.13 & 4.25 \\
\hline Data & Data Gaps & Non-State Actors & 4.13 & 4.25 \\
\hline Methodology & Developing & $\begin{array}{l}\text { Meet QUICK-TURN information } \\
\text { needs of decision makers }\end{array}$ & 4.00 & 3.75 \\
\hline Methodology & Domains & Irregular Challenges & 3.94 & 4.25 \\
\hline Methodology & Developing & $\begin{array}{l}\text { Explicitly address RISK \& } \\
\text { UNCERTAINTY }\end{array}$ & 3.94 & 4.13 \\
\hline Methodology & Domains & $\begin{array}{l}\text { Stability, Security, Transition, \& } \\
\text { Reconstruction (SSTR) }\end{array}$ & 3.88 & 4.13 \\
\hline
\end{tabular}

\section{Potential Solutions, Irregular Warfare and Global War on Terrorism (IW/GWOT)}

The area of IW/GWOT dominated the high priority gaps identified by the community. Major shortfalls exist in the areas of methodology, tools, data, and intellectual capital. The wide range of gaps suggests that a few narrow, highly focused initiatives would be insufficient to address the broad requirements for credible M\&S in this area. In fact, the results suggest that a Center of Excellence (COE) should be created within the Department to address the full range of issues associated IW/GWOT. There are several options that could be pursued to achieve that goal. These include building on existing University Affiliated Research Centers (UARCs) or Federally Funded Research and Development Centers (FFRDCs) that are currently addressing IW/GWOT issues to create a more unified COE approach. A second option would be to create a new UARC or FFRDC whose charter would be limited to IW/GWOT issues. A third option would be to leverage an emerging organization such as the interagency Center for Complex Operations (CCO) that is currently being established to focus on SSTR issues. Since the primary focus of CCO is on SSTR, adding IW/GWOT issues to their agenda might defocus the organization and limit its ability to make meaningful progress in any area. Such an IW/GWOT COE could connect a number of the organizations currently doing work in this area and be connected to like organizations in other nations to provide joint, coalition approaches to various aspects of challenges associated with this area of military operations. Such a Center 
or set of interconnected Centers could be monitored by a DoD Board of Directors representing the various communities to help monitor and guide their work.

In the near future, it would be useful to conduct a concise, focused study to clarify the consequences of these, or alternative, options. Such a study should address the potential quality, responsiveness, and resource implications of the candidate options. At the same time, there are several steps other that could be taken to address selected high priority IW/GWOT gaps even before a COE is established. As an immediate step, the Analysis Community should take action to enhance collaboration among the researchers that are already addressing this subject area. For example, in the response to the action officer survey promulgated in early 2007 as part of the business planning process, a substantial number of activities reported that they are currently working on the formulation of Measures of Merit for IW/GWOT. The JADM SC could charter a Community of Interest (CoI) to connect these activities and encourage the involved researchers to meet periodically to discuss relevant methodologies, tools, data, research needs, and intellectual capital. If this CoI proves unwieldy, an alternative would be to create separate working groups made up of subsets of these activities that could be further divided to focus on individual nations or regions.

Similarly, participants at the March 2007 workshop observed that there are numerous data exchange agreements that exist between the US and other countries. These agreements should be reviewed to encourage greater collaboration on IW/GWOT issues. In particular, efforts should be made to strengthen the intellectual links with researchers, such as those in the United Kingdom, who bring extensive background in IW/GWOT issues, such as British operations in Malaysia and Northern Ireland.

In fact, there are a number of useful, but fragmented IW/GWOT initiatives that are already underway at Defense Agencies and in academia. However, in the absence of an overarching framework, these individual initiatives have not achieved "critical mass." To redress this problem, a combined "top-down, bottom-up" approach could be implemented. This process would begin with the formulation of an overarching framework within which individual initiatives would be embedded. At the next stage, the framework would be populated with selected initiatives. At least four candidate initiatives could serve as a point of departure. At the Defense Advanced Research Projects Agency (DARPA), the Conflict Modeling, Planning and Outcomes Experimentation (COMPOEX) is developing individual PMESII models that can be composed into appropriate societal models. One of the key features of this initiative is the implementation of a verification, validation, and accreditation (VV\&A) process that is consistent with the timeframes of interest. At the Defense Threat Reduction Agency (DTRA), a Joint Threat Anticipation Center (JTAC) is being created with the assistance of Argonne National Labs and the University of Chicago. A third initiative is being conducted at Carnegie Mellon University, where a faculty member is directing 


\section{Longer Term IW Solutions}

- Establish new demand tasking for the Intelligence Community

- Request that they monitor and report on common-place activities (e.g., market places, schools) in areas of interest

- Focus data gathering to better support new tool requirements (cultural, anthropological, human factor understanding

- Build the PMESII-analogue to the conventional "pyramid" of M\&S tools; e.g.,

- From systems engineering models to campaign models

- Enlist appropriate subject matter experts to provide knowledge, expertise

Needed: A PMESII

"Pyramid"

\author{
new

(1)

Figure 6: Longer-term Irregular Warfare Solutions.

a Computational Analysis Social and Organization Sciences (CASOS) initiative. Finally, at the National Defense University (NDU), a Computational Social Science program is developing tools such as Senturion that support the identification and assessment of potential conflict issues. Once efforts such as these are embedded in the framework, it would be appropriate to go "top down" to refine the framework and identify potential areas of collaboration, isolate potential voids, and encourage efforts to redress these shortfalls.

At the same time, the Joint Data System (JDS) currently hosts a Counter Insurgency (COIN) Forum on its web site. While useful, this initiative requires greater visibility. For example, if the dialogue that has taken place at the M\&S workshop and in the succeeding months had been captured in the COIN Forum, it could have more effectively exposed the discussion and insights to a much larger participatory audience.

Longer-term irregular warfare solutions are suggested in Figure 6. These acknowledge shortfalls in the current collaboration between the analysis M\&S community and the Intelligence Community (IC) and suggest the development of a basic database and hierarchical set of tools to address irregular warfare issues. In fact, the assistance of the IC is essential to provide the data needed to satisfy the requirements of emerging PMESII tools. In addition, DoD leadership needs to task the IC to monitor commonplace activities (e.g., activity in the market place; flow of actions around schools), to 
provide timely insight into disruptions into community patterns and their consequences.

In dealing with traditional challenges, the analysis community has historically conceptualized M\&S tools as a pyramid. At the base of the pyramid are highly granular, systems engineering tools. As one ascends the pyramid, the tools of interest include engagement, mission, and campaign-level M\&S. Over time, the layers of the pyramid are enriched by the implementation of improved tools with linkages among the layers of the pyramid developed and refined. An analogous pyramid is envisioned for IW/GWOT. However, since the social science theory that is the foundation for PMESII tools is not well articulated and documented, the first step it to assemble data and the available theory as the base of the pyramid. At the next level of the pyramid, the individual PMESII tools should be assembled and linked to the appropriate elements of social science theory. Individual tools may be packaged in a variety of ways (e.g., generic; appropriate for a selected region or nation). At the top of the pyramid, composed societal M\&S could be created that is drawn from theory-consistent, individual PMESII M\&S. In view of the military analytic community's limited knowledge about the social sciences, it will be important to have access to subject matter experts (SMEs) who can provide critical insights. Note, that a variety of SMEs will be needed that transcend disciplinary knowledge to include an understanding of the interactions that are likely to occur across disciplines. The proposed Center of Excellence for IW/GWOT would play a major role in creating and evolving the intellectual capital encapsulated in this pyramid.

\section{Potential Solutions, Stability, Security, Transition and Reconstruction}

The analysis of SSTR issues is extremely complex. It requires a multidimensional approach, subsuming many areas of interest, such as security, governance and participation, social and economic well-being, justice and reconciliation, and many stakeholders, to include host nation, non-governmental organizations, international organizations, multiple US government activities, and coalition partners. Furthermore, the problems vary over time as the state of the nation in crisis evolves from initial response, to transformation, to fostering sustainability. A SSTR Center of Excellence can bring important cross disciplinary focus to dealing with a problem of this complexity. One way to establish such a Center of Excellence would be to build on the capability that is already to be instantiated in the Center for Complex Operations. The CCO is planned to be an interagency activity that would draw on the leadership of the Department of Defense, the Department of State, and the United States Agency for International Development (USAID). The Center is envisioned as a network of US Government organizations that currently conduct SSTR research, education, and training. However, if it is to be useful to the analysis community, it is important that it 
be augmented with individuals that are well-versed in strategic analysis methodologies and tools. One source of tools could be the United States Pacific Command's Peace Operations Support Tool (POST) as well as those used by other major US and allied commands to address the range of SSTR issues.

A foundation for this $\mathrm{COE}$ would be the accumulation and sustainment of credible SSTR data. There are a number of sources that could contribute to this need. For example, useful information can be derived from World Values surveys. In addition, a great deal of work has been performed recently to structure and populate PMESII data for selected areas of the world, such as DoD's Cultural Preparation of the Environment (CPE) project, with work continuing to expand upon that base through projects such as the Army's Human Terrain System. Furthermore, other organizations, such as the State Department's Humanitarian Information Unit (HIU), have useful information to contribute. While these sources provide a useful start, there are undoubtedly other sources available in academia and through international or allied bodies that can contribute. In addition, real time insight and information could be collected from the training community exercises and wargames. In fact, an important step would be to ensure that the results from those activities are made available to the analysis M\&S community conducting SSTR research.

Gaps that must be addressed by any initiatives in this area include limited understanding of the underlying social science theory; insufficient data sources that address the effects of behavior, training, leadership, and other important factors; a lack of tools that capture requirements and effects of stability operations; a shortage of reliable stability models and indicators; and limitations in the measures of merit used to assess capabilities and progress in SSTR operations.

There are a number of emerging capabilities that may address some of these gaps. These include the application of systems dynamics models such as those developed by the Massachusetts Institute of Technology, the United Kingdom's Peace Support Operations Model, or other models focused on cultural and human factor interactions, to include Purdue's Synthetic Environment for Analysis \& Simulation (SEAS). The Office of the Undersecretary of Defense (Intelligence) through its Special Operations and Low Intensity Conflict Directorate has established an Integrated Product Team to review approaches and initiatives in this area, which could be a rich source of insight for researchers working in this area. Another initiative that will contribute is the PA\&E sponsored set of wargames (GWOT X-GAME) that provides a venue for eliciting subject matter inputs on various aspects of related military operations. In fact, PA\&E has a sponsored research project underway to better understand human behavior and its impact across a range of military operations. In addition, the US Navy has taken the lead in developing a military-focused Irregular Warfare Model. The US Marine Corps is leading a separate activity to investigate methods for the validation, 
verification and accreditation of agent-based models, which could become a source for both SSTR and IW/GWOT tool development. The Under Secretary of Defense for Policy is developing an Irregular Warfare Roadmap which will also contribute to both areas of research. Finally, the Office of the Under Secretary of Defense for Acquisition, Technology and Logistics is initiating a major effort to better understand Human Social Cultural Behavior (HSCB).

\section{Potential Solutions, Joint Interagency and Multinational (JIM) Issues}

The 2006 Quadrennial Defense Review stated that, "The Department of Defense cannot meet today's complex challenges alone. Success requires unified statecraft: the ability of the U.S. Government to bring to bear all elements of national power at home and to work in close cooperation with allies and partners abroad." ${ }^{2}$

Several gaps must be closed in order to develop M\&S that supports improved analysis of JIM issues. Currently, military analysts lack a full understanding of capabilities that other key actors, such as interagency partners, allies, NGOs, and International Organizations, bring to specific operations or crisis response activities. In addition, they have a limited understanding of the interagency environment and how to effectively integrate the application of the full range of national power instruments in the conduct of such operations. This is exacerbated by a limited understanding of underlying social science and human behavior theories as they apply to military operations. Because of these gaps, military analysts have not developed the tools to apply to the analysis of such operations, nor do they have an adequate outreach to interagency partners, allies, and others who could provide direct assistance in this arena.

As noted earlier, the $\mathrm{CCO}$ will help to address some of these gaps. Tools, such as the UK's Peace Support Operations Model (PSOM) and PACOM's POST are available to serve as an initial basis for addressing JIM issues, but much more needs to be done. Projects, such as those enumerated in the SSTR section, will contribute to JIM as well. In addition, the Office of the Under Secretary for Policy is leading a project to develop unclassified defense planning scenarios which could serve as a basis for sharing JIM information across agency and allied borders. To assist in the collaborative development of pertinent information, the Department should also review data exchange agreements with other agencies and governments to facilitate collaboration. In addition, it should participate in the development of a core set of M\&S that enhances joint, interagency, and multinational (JIM) analyses. Finally, as with the IW/GWOT and SSTR activities, it needs to help gather and develop authoritative data that addresses a full range of political, economic, social, information, and infrastructure issues that can be shared between JIM analysts. 


\section{Summary}

In response to changes in the international security environment, the US Department of Defense has recognized the need to change its overarching national security strategy as well as its approach to developing, managing, and applying M\&S to the development and assessment of options associated with the new emerging security environment. It has established a new structure to oversee $\mathrm{M} \& \mathrm{~S}$ activity and has directed DoD communities to develop business plans to focus that effort. The Analysis Community has responded by identifying desired analytic M\&S goals, measuring current capabilities, prioritizing capability gaps, and then outlining potential solutions. These activities are being captured as part of a "living" analysis M\&S business plan product and process. Solutions are being developed and refined, to be discussed and finalized by the appropriate oversight board. Many solutions will require collaboration with both the interagency and allied communities, to more effectively create and integrate forces to meet strategic challenges of the $21^{\text {st }}$ Century. This paper notes that some of the key desired outcomes are improved M\&S to address three areas of particular concern: Irregular Warfare and the Global War on Terror; Stability, Security, Transition and Reconstruction operations; and Joint, Interagency, and Multinational operations. In these areas of mutual interest, the Department is seeking a broad, collaborative approach to both engage interagency and allied partners, and to ensure the analytic approaches and tools that emerge can be used by all members of the community. 


\section{Notes:}

1 Dr. Allen is the Deputy Director of the Joint Advanced Warfighting Division, Institute of Defense Analyses, Alexandria, Virginia. He is a former commander of the Air Force Studies and Analysis Agency and co-author of The DoD Analysis Modeling and Simulation Master Plan, August, 2007.

2 U.S. Department of Defense, Quadrennial Defense Review Report, 6February 2006, <www.forscom.army.mil/reeng/1-PMD/2006QDR.pdf>, p. 83.

THOMAS L. ALLEN is a 1969 graduate of the United States Air Force Academy who received a doctorate in Economics and Operations Research from the Massachusetts Institute of Technology in 1972. He served 29 years in the Air Force as a T-38 instructor pilot, F-15 fighter pilot, staff officer, composite wing commander and finally commander of the Air Force Studies and Analyses Agency. He was stationed in both the Pacific and European theaters, serving in Okinawa, Korea, the Netherlands, England and Iceland. In 1998, he retired from active duty and joined the staff of the Institute for Defense Analyses. His research work includes directed energy weapons technology; fighter and airlift fleet enhancements; lessons learned from Kosovo, Operation Enduring Freedom, and Operation Iraqi Freedom; aviation safety concepts and technologies; joint enabling military capabilities; improvised explosive device defeat; military modeling and simulation; and irregular warfare. He was the director of the Joint Forces Command Urban Resolve 2005 experiment and he currently serves as the deputy director of IDA's Joint Advanced Warfighting Division. He is a former president and elected fellow of the Military Operations Research Society. 